\title{
DETERMINATION OF MANGANESE AS SULPHATE AND BY THE SODIUM BISMUTHATE METHOD
}

\author{
By William Blum
}

CONTENTS

I. INTRODUCTION . . .

r. Importance of accurate manganese determinations........... $\eta_{1} 6$

2. Sources of error in gravimetric methods................... 716

3. Sources of error in volumetric methods................... $7 \mathrm{I} 7$

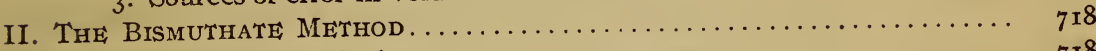

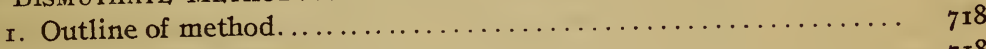

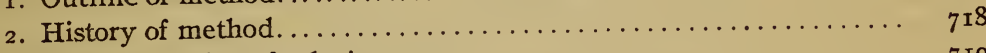

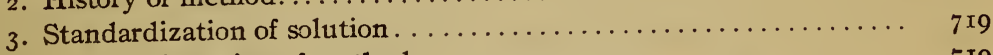

(a) Discussion of methods...................... 7 I9

(b) Evidence based on reduction and reoxidation........... 7 I9

4. Preparation of materials and solutions.................. 720

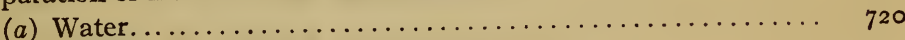

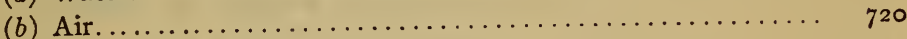

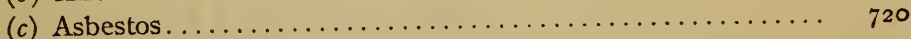

(d) Potassium permanganate............................... 721

(e) Permanganate solutions............................

(f) Stability of permanganate solutions . . . . . . . .

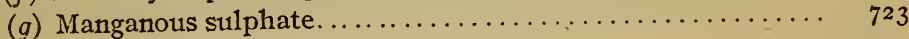

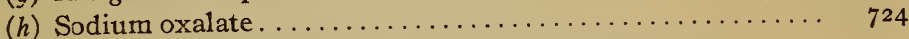

(i) Ferrous sulphate solutions-Stability ............. 724

(j) Nitric acid................................ 724

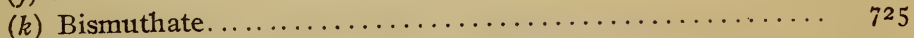

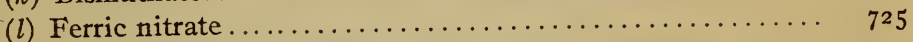

(m) Use of weight burettes......................... 725

5. Standardization of permanganate with sodium oxalate......... $\quad 7_{226}$

6. Standardization of permanganate with manganous sulphate...... 727

(a) Standardization of manganous sulphate solutions........ 727

(b) Effect of conditions upon the standardizations with manganous sulphate. ........................ 730

(I) Ferrous sulphate-permanganate ratio........... 730

(2) Amount of manganese present in a determination... 732

(3) Acidity, volume, time of standing, etc......... 734

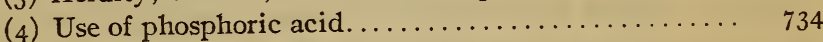

(c) Probabie course of reactions ....................... 735

(d) Conditions recommended........................ 736

7. Agreement of values derived from sodium oxalate and manganese

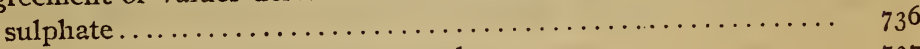

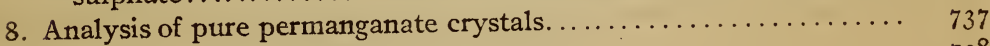

9. Analysis of manganese ores. . . . . . . . . . . . . . . .

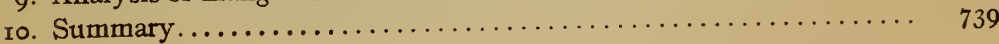




\section{INTRODUCTION}

\section{IMPORTANCE OF ACCURATE MANGANESE DETERMINATIONS}

In spite of the large number of methods in use for the determination of this important element, results by different methods and different chemists seldom show satisfactory agreement. While differences of as much as a few per cent of the manganese present have little commercial significance in iron and steel containing I per cent or less of manganese, the highest possible accuracy is demanded in the analysis of high-grade materials such as manganese ore and ferromanganese, of which large amounts enter into commerce, at prices dependent upon the results of analysis. For example, imports of manganese ore by this country in I9I I amounted to I 76852 long tons, valued at \$I I86 79I. It can readily be seen that a constant error of $\mathrm{I}$ per cent in the analyses of such material may cause a considerable difference in the total amount paid for the ores. That constant errors of such magnitude are possible with our present methods will be shown in this paper.

\section{SOURCES OF ERROR IN GRAVIMETRIC METHODS}

Even with the greatest care the gravimetric results are not necessarily accurate, due not alone to the possibilities of losses by solubility of precipitates; and of too high weight due to contamination from vessels or reagents; but also to uncertainty in the composition of the precipitates as weighed. The three forms in which manganese is most commonly determined gravimetrically are $\mathrm{Mn}_{3} \mathrm{O}_{4}, \mathrm{Mn}_{2} \mathrm{P}_{2} \mathrm{O}_{7}$ and $\mathrm{MnSO}_{4}$. It is generally admitted that the first of these is unsatisfactory, as the composition depends directly upon the temperature of the ignition and the nature of the atmosphere surrounding the precipitate. Even under carefully regulated conditions Raikow and Tischkow ${ }^{1}$ could not obtain results which agreed to better than I part in 200. Gooch 
and Austin ${ }^{2}$ have shown that the composition of manganese "pyrophosphate" depends upon the content of ammon:um salts and ammonia, and the temperature, volume, and method of precipitation of the manganese ammonium phosphate. Even under the conditions which they recommend, their errors amounted in some cases to I per cent of the manganese present, and were in general too high. The method can not, therefore, be considered satisfactory for highly accurate work, and certainly not for obtaining a known amount of manganese to serve as a primary standard. Experiments described in this paper have led to the conclusion that manganous sulphate, obtained under proper conditions, is the most accurate form in which this element can be weighed, both in gravimetric analysis and in securing a known amount of manganese.

\section{SOURCES OF ERROR IN VOLUMETRIC METHODS}

The difficulty of securing a known amount of manganese to serve as a primary standard has hindered the accurate investigation of the great number of volumetric methods which have been proposed. In most cases they have been tested by comparison with methods, gravimetric or volumetric, which had not been shown to be intrinsically accurate. This fact, together with the usual dependence of the results of such methods upon the precise conditions of operation, has led to the publication of a large number of contradictory papers upon these methods. For example, the Volhard method and its various modifications has been the subject of over 50 investigations since its publication in 1879 . It is generally admitted that the results by this method are low unless an empirical factor dependent upon the conditions of operation, is employed, though some investigators have obtained theoretical results under certain conditions. In view of the above situation, it is highly desirable to find some method which will yield results of known accuracy, which are not closely dependent upon the exact conditions of operation, and which may serve to test other methods. 


\section{THE BISMUTHATE METHOD}

\section{OUTLINE OF METHOD}

Of various methods considered, the bismuthate appeared most promising, and has been found to entirely fulfill the above requirements. In this method the manganese in nitric acid solution is oxidized with sodium bismuthate, of which the excess is removed by filtration through asbestos. To the resulting permanganic acid is added a measured excess of ferrous sulphate solution, which is then titrated with permanganate of known strength and of known ratio to the ferrous solution. The investigation therefore resolved itself into a study of the methods of standardizing the permanganate employed in the final titration and the influence of the various conditions of operation upon the results obtained by the bismuthate method.

\section{HISTORY OF METHOD}

The method as originally prepared by Schneider $^{3}$ depended upon the use of bismuth tetroxide as the oxidizing agent and titration of the permanganate acid with hydrogen peroxide. In this form the method was employed by Campredon, ${ }^{4}$ Mignot $^{5}$ and Jaboulay: $^{6}$ Reddrop and Ramage ${ }^{7}$ modified it by employing sodium bismuthate, which was more readily obtained free from chlorine, and suggested filtration of the permanganate acid directly into the hydrogen peroxide. On account of the instability of the latter reagent Ibbotson and Brearley ${ }^{8}$ replaced it by ferrous ammonium sulphate, in which form the method has been since used, being described in detail by Blair, ${ }^{9}$ whose directions for this method are generally followed in this country.

${ }^{3}$ Ding. Poly. J., 269, p. 224; 1888.

4 Rev. Chim. Indust., 9, p. 306; 1898.

${ }^{5}$ Ann. Chim. Anal., 5, p. I72; 1900.

${ }^{6}$ Rev. gen. chim., 6, p. I19; 1903.

7 J. Chem. Soc., 67, p. 268; 1895 .

8 Chem. News, 81, p. 247; r9or.

'J. Am. Chem. Soc., 26, p. 793; 1904 and Chemical Analysis of Iron, 6th and 7tin ed. 


\section{STANDARDIZATION OF SOLUTION}

(a) Discussion of Methods.-As above stated the accuracy of any such volumetric method depends principally upon the method of standardization employed. Blair ${ }^{10}$ mentions in his book three methods, viz, (a) calculation from the iron value, (b) use of a steel of known content, and (c) use of a known amount of manganous sulphate, without expressing any preference, or opinions as to their relative accuracy. Standardization by means of sodium oxalate may be included under (a) since values found with this standard under proper conditions ${ }^{11}$ have been found at this Bureau to agree with iron values within I part in $\mathrm{I}, 000 .{ }^{12}$ Method (b) is a secondary method and is evidently unsuitable for work of high accuracy. As will be shown later, the standardization of manganous sulphate is a tedious operation and subject to considerable errors. For this reason sodium oxalate was considered at this Bureau to be the most convenient and accurate standard for this method. Brinton, ${ }^{13}$ however, stated that there was a difference of I per cent (at first stated as over 3 per cent) between the values based upon sodium oxalate and manganese sulphate, respectively. In a paper from this Bureau by Dr. W. F. Hillebrand and the author ${ }^{14}$ the reasons for our belief in the accuracy of the sodium oxalate standard were expressed in the form of a preliminary paper, the conclusions of which have been verified by subsequent investigations described in this paper.

(b) Evidence Based on Reduction and Reoxidation.-The original basis of our use of the sodium oxalate standard for this method was the fact that if a definite amount of a permanganate solution be reduced and then reoxidized by means of the bismuthate method, it is exactly equivalent in oxidizing power to the original permanganate. This experiment was based upon a

\footnotetext{
${ }^{10}$ In the appendix of the rgr2 edition, p. 330, Blair recommends the standardization with sodium oxalate, under approximately the conditions given by $\mathrm{McBride}$, as the most accurate method; a conclusion based upon the work described in this paper.

11 McBride: J. Am. Chem. Soc., 34, p. 4I5; I9I2.

12 See Bureau of Standards Certificate for Sibley Iron Ore, Standard Sample 27.

${ }^{13} \mathrm{~J}$. Ind. Eng. Chem., 3, pp. 237 and 376 ; $191 x$.

${ }_{14} \mathrm{~J}$. Ind. Eng. Chem., 3, p. 374; $191 x$. $73764^{\circ}-\mathrm{I} 3-8$
} 
similar one suggested by Wolff ${ }^{15}$ and employed by de Koninck ${ }^{16}$ for testing the accuracy of the Volhard method for manganese. Its significance as applied to the bismuthate method is that the manganese is oxidized to the same state of oxidation as was originally present in the permanganate, theoretically $\mathrm{Mn}^{\mathrm{VII}}$. In the absence of evidence to the contrary it seems highly improbable that any appreciable manganese can be present in a filtered permanganate-solution in a form other than Min ${ }^{\mathrm{VII}}$, and still less probable that in an entirely different medium the manganese should be oxidized by bismuthate to the same state of oxidation, other than Min VII. Since, however, at least two persons in addition to Brinton had observed a discrepancy of the order of I per cent between the sodium oxalate and manganese sulphate values, the subject deserved further investigation; not alone from the standpoint of the manganese determination, but also as possibly throwing light upon the composition of permanganate solutions and their action as oxidizing agents. At this point it may be mentioned that the original observations regarding the reduction and reoxidation of the permanganate have been confirmed entirely, with solutions $A_{1}$, B, E and G, prepared as shown on page 722 .

\section{PREPARATION OF MATERIALS AND SOLUTIONS}

(a) Water.-Water used in the purification of permanganate and in the preparation of all the permanganate solutions except I and $\mathrm{K}$ was distilled three times, the last two being from alkaline permanganate. Water used for the rest of the work was ordinary distilled water of good grade.

(b) Air.-The air used to deliver the solutions from the stock bottles was washed with acid bichromate solution and alkaline permanganate followed by a column of glass wool.

(c) Asbestos.-The asbestos used in the filtration of the permanganate solutions and in the bismuthate method, was digested for several days with hydrochloric acid, which was finally removed by thorough washing with hot water. It was then suspended in water and the finest portions separated and used in this work. For a few of the experiments this asbestos was ignited, without 
making, however, any appreciable difference in the results. A 2-inch platinum cone, arranged as suggested by Blair, ${ }^{17}$ was used for preparing the filter.

(d) Potassium Permanganate.-Two commercial samples of potassium permanganate were employed, Baker and Adamson's C. P. salt, and Kahlbaum's " $\mathrm{K}$ " grade. A portion of the former was purified by two recrystallizations in Jena glass flasks, the solutions being electrically heated, and filtered through ignited asbestos just before being allowed to crystallize. The fine crystals so obtained were sucked dry on a platinum cone and were then exposed in a thin layer in the dark for four weeks in a vacuum dessicator over concentrated sulphuric acid, the vacuum being maintained at approximately $2 \mathrm{~cm}$. In spite of this long drying, the material was found to contain 0.38 per cent water as determined by heating to decomposition and collecting the water in a weighed calcium chloride tube. When dissolved in pure water and immediately filtered through asbestos, the solution left a slight stain upon the filter. After thorough washing this stain was dissolved off with sulphurous acid, and its manganese content determined colorimetrically, being equal to about o.or per cent, i. e., a negligible quantity. Numerous attempts to prepare a permanganate solution which would leave absolutely no stain upon asbestos proved unsuccessful. Whether such stains were due to the action of the asbestos itself as claimed by Tscheishvili ${ }^{18}$, or to reduction of the permanganate by traces of dust or other reducing substances, could not be determined. The amount of such reduction was, however, negligible, and far less than that observed by Tscheishvili.

(e) Permanganate Solutions were prepared by dissolving a weighed amount of the salt in water; and in the case of the commercial samples, filtering through asbestos to remove manganese peroxide, etc. They were then made up to a definite weight of solution, since the subsequent analyses were conducted entirely with weight burettes. 
The following solutions were employed in the investigation: TABLE I

Permanganate Solutions Used

\begin{tabular}{|c|c|c|c|c|}
\hline Solution & Approximate strength & $\mathrm{KMnO}_{4}$ & $\mathrm{H}_{2} \mathrm{O}$ & Preserved \\
\hline$A_{1}$ & $0.03 \mathrm{~N}$ & Purified & Purified & Dark \\
\hline $\mathrm{A}_{2}$ & $0.03 \mathrm{~N}$ & “ & “ & “ \\
\hline B & $0.03 N+1 \% \mathrm{KOH}$ & “" & “ & “ \\
\hline$E$ & $0.1 \mathrm{~N}$ & “ & “ & “ \\
\hline G & $0.1 \mathrm{~N}$ & B \& A & “ & “ \\
\hline I & $0.1 \mathrm{~N}$ & “ & Ordinary & Light \\
\hline $\mathrm{K}$ & $0.1 N$ & Kahlbaum & “ & “ \\
\hline
\end{tabular}

These solutions were preserved in stock bottles provided with an inlet and exit tube with ground glass joint as in an ordinary gas wash bottle. To the inlet tube was sealed a U-tube containing some of the same solution as was in the bottle, thereby preventing changes in concentration of the latter. The exit tube was provided with a three-way stopcock and a tip by which the solution could be delivered to the weight burette by means of purified compressed air.

(f) Stability of Permanganate Solutions. - At first it was thought necessary to protect these solutions with black paper, but later experiments showed that in the course of several months no appreciable decomposition took place in the solutions exposed to diffused daylight, provided they were first freed from peroxide and were protected from dust and other reducing substances, and that only purified air entered the bottles. Solution I, for example, prepared from ordinary distilled water, and permanganate containing appreciable peroxide, which was removed by a single filtration through asbestos, did not suffer decomposition within the limits of observation (I part in 2000) on standing for two months without protection from the light; even though it was intentionally exposed to bright sunlight for several hours soon after it was prepared. In connection with this observation, which simply confirms previous work of others, ${ }^{19}$ it is desirable

\footnotetext{
${ }_{19}$ Morse, Hopkins and Walker: Am. Chem. J., 18, p. 40I; I896. Gardner and North: J. Soc. Chem. Ind., 23, p. 599; 1904. Warynski and Tscheishvili: J. Chim. Phys., 6, p. 567; 1908.
} 
to call attention to another point in connection with the stability of permanganate solutions, which so far as I know has not been previously noted, or published. Under conditions which rapidly reduce neutral permanganate solutions, e. g., the presence of dust, reducing gases, or precipitated peroxide, decomposition is greatly retarded by the addition of a small amount of alkali. It was upon the basis of this observation, first noted qualitatively, that Solution B was prepared with I per cent of potassium hydroxide. Results with this solution were entirely satisfactory, but since the other. solutions, when protected from reducing substances, were perfectly stable, the use of alkaline solutions for this work was found unnecessary. Under commercial conditions, however, where it is not always practicable to protect the solutions, the addition of a small amount of alkali will add to their stability.

(g) Manganese Sulphate.-Pure material was prepared from 300 grams of Kahlbaum's crystallized manganese sulphate ("Zur analyse"), the operations being conducted entirely in platinum. It was dissolved in water and filtered to remove a small amount. of insoluble matter. It was next saturated with hydrogen sulphide, producing a small amount of a black precipitate which was found to contain copper. Additional hydrogen sulphide and a small amount of ammonia produced a precipitate entirely pink, which was filtered out. The hydrogen sulphide was expelled, a few drops of sodium hydroxide were added and the solution was boiled and filtered; the precipitate being found to contain iron. This last operation was twice repeated, the third precipitate being free from iron. An excess of pure, freshly prepared ammonium carbonate was then added and the precipitate of $\mathrm{MnCO}_{3}$ washed with hot water, by decantation and suction, till free from sulphate. It was dissolved in a slight excess of hydrochloric acid and crystallized twice as $\mathrm{MnCl}_{2}, 4 \mathrm{H}_{2} \mathrm{O}\left(\right.$ at $\left.-5^{\circ}\right)$. The latter crystals were treated with an excess of sulphuric acid, and heated in a double walled platinum dish till almost all the excess sulphuric acid was expelled. The product was entirely soluble in water, and contained a slight excess of sulphuric acid as determined in subsequent tests (Table II, A, p. 728). 
(h) Sodium Oxalate.-Two samples were employed, one which had been especially purified by the author for a previous investigation, ${ }^{20}$ and a larger sample prepared especially for this Bureau, and which was found to have a reducing value equal to the former, within the limits of I part in 2000.

(i) Ferrous Sulphate and ferrous-ammonium sulphate were employed indiscriminately after it was found that the solutions possessed about the same stability. The C. P. salts as purchased were employed, since their exact composition was not important. For use with $0.03 N$ permanganate, the solution was prepared according to Blair, with $\mathrm{I} 2.4 \mathrm{~g}$ ferrous-ammonium sulphate (or $8.8 \mathrm{~g}$ crystallized ferrous sulphate) and $50 \mathrm{cc}$ concentrated sulphuric acid per kilogram of solution. For use with o.I $N$ permanganate, a solution containing $39.2 \mathrm{~g}$ ferrous-ammonium sulphate (or $27.8 \mathrm{~g}$ ferrous sulphate) and $50 \mathrm{cc}$ concentrated sulphuric acid per kilogram was prepared. If phosphoric acid was employed, as recommended by Dudley, ${ }^{21}$ it replaced half of the sulphuric acid in the $0.03 N$ solutions; but was added in addition to the regular amount of sulphuric acid in the o.I $N$ solutions.

Stability of the ferrous sulphate solution.-Incidental observations upon the change in strength of $0.03 N$ ferrous ammonium sulphate indicated that the rate of oxidation, though slow, was erratic, due no doubt to variation in the extent of its exposure to air. With o.I $N$ ferrous sulphate and ferrous ammonium sulphate, the daily rate of oxidation under the conditions used was approximately I part in 500 , i. e., about I per cent in five days, over considerable periods. This rate will depend no doubt upon the conditions of its preservation, and is of interest only as indicating how often its strength should be checked up for work of any desired degree of accuracy. Ratios obtained at the beginning and end of various series of determinations showed that no appreciable change took place in a period of a few hours, thus confirning the observation of Baskerville and Stevenson. ${ }^{22}$

(j) Nitric Acid of regular C. P. grade was employed; in the concentrated form, and diluted to 25 per cent and 3 per cent by vol-

${ }^{20}$ Blum: J. Am. Chem. Soc., 31, p. 123; I9r2.

${ }^{21}$ Blair: Chemical Analysis of Iron, gth ed., p. I25.

${ }^{22}$ J. Am. Chem. Soc., 33, p. IIO4; I9Ir. 
ume. The former two solutions were preserved in the dark, since it has been recently shown by Reynolds and Taylor ${ }^{23}$ that nitric acid as weak as ro per cent is decomposed by light, but that recombination takes place in the dark.

(k) Bismuthate.-Two samples of C. P. sodium bismuthate were employed, one from Baker and Adamson and one from Eimer and Amend. These two samples differed very markedly in appearance, the former being dark brown, and the other yellow. In spite of this fact, no difference could be detected between them as regards their suitability for this oxidation. It is well to mention however that this compound, of more or less indefinite composition, is somewhat unstable, and if preserved for over six months should be tested for its efficiency of oxidation.

(l) Ferric Nitrate.-In order to test the effect of ferric salts upon this method, it was necessary to obtain iron, or some salt of iron which was free or practically free from manganese. This proved to be a difficult task, and after testing American ingot iron, and a large number of ferrous and ferric salts, the only one found satisfactory was a sample of Merck's crystallized ferric chloride, which contained less than o.oor per cent manganese. To convert this to nitrate, it was first converted to sulphate by evaporation to the appearance of fumes with an excess of sulphuric acid, and the sulphate was precipitated with ammonia, washed and dissolved in nitric acid. The resulting salt was free from chloride (of which traces interfere in the bismuthate method) and contained only a small amount of sulphate (which is without effect on this method).

(m) Use of Weight Burettes.-Simple weight burettes were made by drawing down the tips of cylindrical graduated separatory funnels ( 50 and $100 \mathrm{cc}$ ). The increased accuracy gained by the use of weight burettes is especially desirable in an operation involving a back titration, and also the ratio of the two solutions used. Weighings were usually made to o.org, except in the case of the smaller amounts of manganese sulphate solutions, which were weighed to $0.005 \mathrm{~g}$ or in some cases $0.001 \mathrm{~g}$. The titrations were usually made in Erlemmeyer flasks of convenient size. 


\section{STANDARDIZATION OF PERMANGANATE WITH SODIUM OXALATE}

Nothing is to be added to the conclusions of McBride, ${ }^{24}$ except to emphasize their relation to the present problem. The conditions recommended by him for the standardization of o.I $N$ permanganate are briefly as follows: Volume of $250 \mathrm{cc}$; acidity 2 per cent sulphuric acid by volume; initial temperature, $80^{\circ}$ to $90^{\circ}$; slow addition of permanganate, especially at beginning and end; final temperature not less than $60^{\circ}$; and end point correction by comparison with a blank containing a known amount of the permanganate. His statement that the variation in results over a wide range of conditions does not exceed I part in rooo, applies to titrations involving the use of about $50 \mathrm{cc}$ of o.I $N$ permanganate. If, however, $0.03 N$ permanganate, commonly used in the bismuthate method, is standardized with sodium oxalate, slight variations in the conditions may cause a relatively much larger error, especially if as is not uncommon, only about $25 \mathrm{cc}$ of permanganate is employed. For standardization of $0.03 \mathrm{~N}$ permanganate, the conditions of McBride were employed, except that the initial volume was $75 \mathrm{cc}$ instead of $250 \mathrm{cc}$, i. e., the oxalate concentration was about the same as for o.I $N$ permanganate. In this way the uncertainty in the end point caused by titrating in a large volume with weak permanganate, can be reduced to a minimum. For accurate work, however, the end point correction should be made, since the object of this titration is to determine the absolute oxidizing power of the permanganate. With so small a volume of solution it is usually necessary to reheat it to $60^{\circ}$ to $70^{\circ}$ before completing the titration. These conditions, as shown by $\mathrm{McBride}$, represent a minimum consumption of permanganate, i. e., the iron or manganese values are a maximum. Any deviation from these conditions will tend to lower the iron or manganese values, which it is believed accounts in part for the discrepancy noted by Brinton an'd others between values derived from sodium oxalate and from manganese sulphate. For calculation of the manganese value from the sodium oxalate, the factor 0.16397 was employed. 


\section{STANDARDIZATION OF PERMANGANATE WITH MANGANOUS SULPHATE}

(a) Standardization of Manganous Sulphate Solutions.-The two methods commonly used for determining the strength of a manganous sulphate solution are $(a)$ precipitation as manganese ammonium phosphate and ignition to pyrophosphate, and (b) evaporation of the solution and heating the residue to a certain temperature. Unfortunately both of these will yield high results if the solution contains substances other than manganese sulphate; whether in the original salt or derived from the glass in which the solution is preserved. But even with pure solutions the results are of uncertain accuracy, especially in the case of the pyrophosphate as above mentioned (p. 7 7 ). Weighing as sulphate was therefore adopted as a means of securing a known amount of manganese. The chief source of uncertainty here is the temperature of the final heating, a point upon which the evidence is rather uncertain and contradictory. Volhard ${ }^{25}$ was able to obtain constant weight with a special burner, but not with a Bunsen burner. Marignac ${ }^{26}$ determined the atomic weight of manganese by heating the sulphate "nearly to red heat." Meineke ${ }^{27}$ determined this element as the sulphate, which after being heated to a temperature not stated, was completely soluble in water. Friedheim ${ }^{28}$ heated the salt to $360^{\circ}$ to $400^{\circ}$, while Gooch and Austin ${ }^{29}$ obtained constant weight by heating in double crucibles, $1 \mathrm{~cm}$ apart, the outer one being at red heat, a procedure since recommended by Treadwell. ${ }^{30}$ In determining the water of crystzallization of the various hydrates of manganous sulphate, Thorpe and Watts ${ }^{31}$ heated the salt to $280^{\circ}$, Linebarger ${ }^{32}$ to $170^{\circ}$ to $180^{\circ}$ and Cottrell ${ }^{33}$ to $270^{\circ}$ to $280^{\circ}$, though the latter found that no decomposition took place at $350^{\circ}$. Richards and Fraprie ${ }^{34}$ showed however that as much as $0 . \mathrm{I}$ per cent $\mathrm{H}_{2} \mathrm{O}$ remained in the salt after

${ }^{25}$ Ann. Chem., 198, pp. 318-364; 1879.

${ }^{26}$ Arch. Sci. phys. et Nat. [3] 10, p. 25; 1883 .

${ }^{27}$ Chem. Ztg., 9, pp. 1478, 1787; 1885 .

${ }^{28} \mathrm{Z}$. anal. Chem., 38, p. 687; 1899 .

${ }^{29}$ Am. J. Sci., 5, p. 209; 1898.
${ }^{30}$ Treadwell and Hall: Quant. Analysis, II, p. ro4.

31 J. Chem. Soc., 37, p. x13; 1880.

${ }^{22}$ Am. Chem. J., 15, p. 225; 1893 .

${ }^{33} \mathrm{~J}$. Phys. Chem., 4, p. 637; 1900.

34 Am. Chem. J., 26, p. 75; r901. 
heating for one half hour at $350^{\circ}$, but that five minutes heating at $450^{\circ}$ produced complete dehydration without decomposition. Classen ${ }^{35}$ and Blair ${ }^{36}$ recommend heating to dull red; while Fresenius ${ }^{37}$ declares that accurate results can be obtained only by chance, as it is impossible to expel all excess sulphuric acid without decomposing the salt.

The following experiments were conducted to determine the temperature to which manganous sulphate may and must be heated, to expel all the water or excess sulphuric acid and to obtain the normal anhydrous salt. About $2 \mathrm{~g}$ of the salt was heated in an open platinum crucible in a small electrically heated muffle, temperatures of which up to $400^{\circ}$, were measured with a $450^{\circ}$ nitrogen-filled thermometer, and above $400^{\circ}$ with a platinumrhodium thermocouple calibrated at this Bureau. The crucible was kept covered in the desiccator and upon the balance, where it was weighed against a similar crucible as a tare. The results of three series of heatings are shown in Table II, the figures in the last column being calculated from the weight which remained practically constant from $450^{\circ}$ to $500^{\circ}$.

\section{TABLE II}

Temperature of decomposition of manganous sulphate

A

(Manganous sulphate prepared as on p. 723)

\begin{tabular}{c|c|c|c|c}
\hline $\begin{array}{c}\text { Tempera- } \\
\text { ture ( }{ }^{\circ} \mathrm{C} \text { ) }\end{array}$ & $\begin{array}{c}\text { Time } \\
\text { (hours) }\end{array}$ & $\begin{array}{c}\text { Weight of } \\
\text { MnSO (g) }\end{array}$ & $\begin{array}{c}\text { Per cent of } \\
\text { constant weight }\end{array}$ & Remarks \\
\hline 300 & 1 & 2.3655 & 100.10 & \\
350 & 16 & 49 & 100.07 & \\
420 & 2 & 42 & 100.04 & \\
420 & 2 & 40 & 100.03 & \\
420 & 17 & 37 & 100.02 & \\
480 & 4 & 33 & 100.00 & \\
480 & 17 & 32 & 100.00 & \\
540 & 4 & 31 & 100.00 & \\
550 & 18 & 29 & 99.99 & \\
620 & 4 & 25 & 99.97 & Slight darkening \\
\hline
\end{tabular}

${ }^{35}$ Ausgew. Meth. d. Analytischen Chem., I, p. $363 . \quad{ }^{37}$ Fresenius-Cohn: Quant. Analysis, I, p. 297.

36 Chem. Analysis of Iron, 7th ed., p. 126. 
The final product was dissolved in water, and the insoluble residue filtered out, washed and ignited, yielding $0.0006 \mathrm{~g} \mathrm{Mn}_{3} \mathrm{O}_{4}$, equivalent to $0.0004 \mathrm{~g} \mathrm{Mn}$, or o.0oI I $\mathrm{g} \mathrm{MnSO}_{4}$. The filtrate was evaporated for series $B$.

\section{B}

\begin{tabular}{c|c|c|c|c}
\hline $\begin{array}{c}\text { Tempera- } \\
\text { ture }\left({ }^{\circ} \mathrm{C}\right)\end{array}$ & $\begin{array}{c}\text { Time } \\
\text { (hours) }\end{array}$ & $\begin{array}{c}\text { Weight } \\
\text { MnSO }(\mathrm{g})\end{array}$ & $\begin{array}{c}\text { Per cent of con- } \\
\text { stant weight }\end{array}$ & Remarks \\
\cline { 1 - 2 } 300 & 3 & 2.3659 & 100.15 & \\
340 & 18 & 44 & 100.10 & \\
400 & 4 & 28 & 100.03 & \\
440 & 18 & 23 & 100.00 & \\
480 & 5 & 22 & 100.00 & \\
480 & 18 & 22 & 100.00 & \\
570 & 5 & 17 & 99.98 & Slight darkening. \\
570 & 18 & 09 & 99.95 & Decided darkening. \\
\hline
\end{tabular}

A few drops $\mathrm{H}_{2} \mathrm{SO}_{3}+\mathrm{H}_{2} \mathrm{SO}_{4}$ were added to the final product, which was then reheated for series $\mathrm{C}$.

C

\begin{tabular}{l|r|r|r|l}
\hline $\begin{array}{c}\text { Tempera- } \\
\text { ture }\left({ }^{\circ} \mathrm{C}\right)\end{array}$ & $\begin{array}{c}\text { Time } \\
\text { (hours) }\end{array}$ & $\begin{array}{c}\text { Weight } \\
\text { MnSO }_{4}(\mathrm{~g})\end{array}$ & $\begin{array}{c}\text { Per cent of con- } \\
\text { stant weight }\end{array}$ & Remarks \\
\hline 300 & 4 & 2.3717 & 100.40 & \\
320 & 17 & 690 & 100.28 & \\
400 & 5 & 41 & 100.08 & \\
400 & 17 & 34 & 100.05 & \\
460 & 5 & 23 & 100.00 & \\
460 & 17 & 23 & 100.00 & \\
525 & 5 & 21 & 99.99 & \\
525 & 17 & 19 & 99.98 & \\
580 & 5 & 17 & 99.97 & Slight darkening. \\
580 & 17 & 08 & 99.94 & Decided darkening. \\
\hline
\end{tabular}

From Table II the following conclusions may be drawn:

(I) Manganous sulphate does not undergo any appreciable decomposition upon prolonged heating to temperatures up to $500^{\circ}$. (2) At temperatures from $550^{\circ}$ to $600^{\circ}$ (from incipient to dull redness) this salt decomposes slowly. (3) The anhydrous normal salt can be obtained only by heating for considerable periods at $450^{\circ}$ to $500^{\circ}$, especially if an excess of sulphuric acid be originally 
present. (4) Attempts to obtain the pure salt by heating directly over a flame, or even in a double crucible, without temperature regulation or measurement, must be subject to considerable uncertainty.

Having now a means for obtaining a known weight of manganous sulphate, solutions of known strength (from 0.002 to $0.005 \mathrm{~g}$ manganese per $\mathrm{g}$ of solution) were prepared by dissolving a known weight of the pure salt, heated to constant weight at $45^{\circ}$ to $500^{\circ}$, and making up to a definite weight of solution, the manganese content of which was calculated by the use of the factor $\mathrm{MnSO}_{4} \rightarrow$ $\mathrm{Mn}=0.3638$. In one case, for example, $5.749 \mathrm{~g}$ pure anhydrous $\mathrm{MnSO}_{4}$ was dissolved in water and the solution made up to exactly I $000 \mathrm{~g}$; producing a solution I $\mathrm{g}$ of which contained 0.00209 I $\mathrm{g} \mathrm{Mn}$, which value was confirmed by evaporation of a weighed portion of the solution and heating to $475^{\circ}$ to constant weight. Determinations made by another chemist upon this solution, by evaporation and heating for a short time to "dull redness", yielded the values $0.002100,2092,2103$, and 2101 ; the mean value 0.002099 being therefore 0.38 per cent too high, i. e. an error of about I part in 250. Upon another solution prepared in the above manner, and containing $0.002000 \mathrm{~g} \mathrm{Mn}$ per solution, the same chemist obtained by direct heating to dull redness $0.002004,2006$ and 2005; i. e. the results were high, in spite of the fact that in the latter series at least, very slight decomposition had evidently taken place in the bottom of the crucible. Apparently therefore those parts of the salt on the sides of the crucible had not been heated to the necessary temperature for a sufficient length of time to expel all water or excess acid. In view of these facts, the desirability of substituting for the manganous sulphate, some other standard, such as sodium oxalate, is very evident.

(b) Effect of Conditions upon Standardization with Manganous Sulphate-(I) Ferrous sulphate-permanganate ratio.-This ratio, which is fundamental for the accuracy of the method, is usually determined by means of a blank experiment; that is, a determination is run through in the absence of manganese, under the conditions to be used in the regular analyses. This procedure, which was evidently devised for the purpose of eliminating errors due to 
impurities in the reagents, has been found to be unnecessary, i. e. the ratio so obtained is the same as that obtained by direct titration of the ferrous sulphate in the same volume. This is due to the fact that on the one hand the bismuthate oxidizes readily any traces of nitrous acid which may be present in the nitric acid, and that on the other hand nitric acid of the strength present in the final solution does not have any effect upon the ferrous salt in the short time necessary for a titration. If, however, the ferrous salt be titrated in the presence of nitric acid containing small amounts of nitrous acid, which has not been treated with bismuthate, an excessive amount of permanganate will be consumed, due to the reducing action of the nitrous acid upon the permanganate, which takes place more rapidly in the presence of ferrous salt than in its absence. It must be clearly understood that conducting the blank experiment in the usual way does not obviate the necessity of avoiding the presence of nitrous acid in the solutions of manganese used in the standardizations or analyses; since, as indicated by Blair ${ }^{38}$, nitrous acid will reduce part of the permanganic acid, precipitating manganese peroxide, which is not reoxidized by the bismuthate.

While not strictly necessary, the determination of this ratio by means of a blank affords a convenient means of testing the efficacy of the filter, and has therefore been followed in all this work. The conditions found most satisfactory are as follows: To $50 \mathrm{cc}$ of nitric acid ( 25 per cent by volume), add a small amount of bismuthate; shake and allow to stand a few minutes, dilute with $50 \mathrm{cc}$ of 3 per cent nitric acid; filter through the asbestos filter and wash with roo $\mathrm{cc}$ of 3 per cent nitric acid. To the filtrate, which should be perfectly clear, add a volume of ferrous sulphate approximately equal to that to be used in the subsequent determinations $(25$ to $50 \mathrm{cc}$ ) and titrate at once to the first visible pink. Even for the most accurate work, no end point correction is required for this titration, provided only that the solutions are always titrated to the same color, and that about the same volumes are used in the standardization and analyses. 
(2) Amount of manganese present in a determination.-One of the serious limitations of this method is the small amount of manganese generally determined, making it somewhat unreliable for high grade materials. Blair recommends the presence of from o.or to $0.02 \mathrm{~g} \mathrm{Mn}$, involving the use of a sample of manganese ore of only $0.02 \mathrm{~g}$, obtained by taking an aliquot of the solution of I $\mathrm{g}$ of the ore. Ibbotson and Brearley ${ }^{39}$ state that the method is equally applicable for large or small amounts of manganese without, however, giving the evidence for this conclusion. Since with $0.03 N$ permanganate, o.or $5 \mathrm{Mn}$ is the largest amount that can be conveniently, determined, the following experiments were conducted with approximately o.I $N \mathrm{KMnO}_{4}$ and $\mathrm{FeSO}_{4}$. The results are expressed in terms of the manganese value of $I \mathrm{~g}$ of the permanganate solution. It should be noted that a high result indicates incomplete oxidation of the manganese by the bismuthate. In these and the following series the following conditions were tentatively employed, and the variation produced by a change of one condition was noted in each series of experiments. The manganese sulphate was oxidized at room temperature in a volume of about $50 \mathrm{cc}$, containing 25 per cent nitric acid by volume. An excess of bismuthate (about $0.5 \mathrm{~g}$ ) was added, the solution was agitated for one minute, the sides of the flask were rinsed down with $50 \mathrm{cc}$ of 3 per cent nitric acid, and the solution at once filtered with suction through the asbestos filter, previously coated with bismuthate. The flask and filter were washed several times with 3 per cent nitric acid of which about Ioo ce was used. The filtration and washing required from one to three minutes. To the filtrate ferrous sulphate was added immediately in slight excess, which was at once titrated with permanganate. 
TABLE III

Effect of Amount of Manganese in the Presence of Variable Amounts of Iron

$\mathrm{KMnO}_{4}$ Solution I

\begin{tabular}{|c|c|c|c|}
\hline \multirow{2}{*}{$\begin{array}{c}\begin{array}{c}\text { Manganese values cal- } \\
\text { culated from sodium } \\
\text { oxalate }\end{array} \\
\begin{array}{l}\text { Values determined over a } \\
\text { period of three weeks }\end{array}\end{array}$} & \multicolumn{3}{|c|}{ Manganese values calculated from manganous sulphate } \\
\hline & $\begin{array}{c}\text { Grams manganese } \\
\text { present }\end{array}$ & Grams iron present & $\begin{array}{c}1 \mathrm{~g} \mathrm{KMnO} \\
\mathrm{g} \mathrm{IMn}\end{array}$ \\
\hline $\begin{array}{r}0.001090 \\
91 \\
92 \\
92 \\
91 \\
91 \\
91 \\
92 \\
91 \\
92 \\
90 \\
90 \\
89 \\
92 \\
91 \\
91 \\
90 \\
90\end{array}$ & $\begin{array}{c}\text { A } \\
0.03 \\
0.03 \\
0.03 \\
0.03 \\
0.03 \\
0.03 \\
\text { B } \\
0.05 \\
0.05 \\
0.05 \\
0.05 \\
0.05 \\
0.05 \\
0.05 \\
0.05 \\
\text { C } \\
0.10 \\
0.10 \\
0.10 \\
0.10 \\
0.10 \\
0.10 \\
0.10 \\
0.10\end{array}$ & $\begin{array}{l}\ldots \\
\ldots . \\
1.0 \\
1.0 \\
1.0 \\
1.0 \\
\\
\ldots \\
\ldots \\
\ldots \\
\ldots \\
\ldots \\
1.0 \\
2.0 \\
3.0 \\
\\
\ldots \\
\ldots \\
\ldots \\
\ldots \\
\ldots \\
\ldots \\
\ldots \\
\ldots\end{array}$ & $\begin{array}{r}0.001088 \\
88 \\
89 \\
89 \\
91 \\
92 \\
\\
90 \\
92 \\
90 \\
87 \\
90 \\
89 \\
90 \\
89 \\
\\
89 \\
89 \\
1161 \\
1089 \\
97 \\
96 \\
1107 \\
1088\end{array}$ \\
\hline Av. 0.001091 & Av. or A \& & 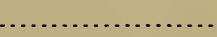 & $\ldots .001089$ \\
\hline
\end{tabular}

From Table III it is evident that for amounts of manganese up to $0.05 \mathrm{~g}$ the method is accurate within the limits of error, i. e. about I part in 500, while results obtained with as much as o. Io $\mathrm{g} \mathrm{Mn}$ are decidedly erratic, only one-half approaching the correct values. It is apparent therefore, that about $0.05 \mathrm{~g} \mathrm{Mn}$ is the practical limit under these conditions. This amount is, however, far more satisfactory than only $0.01-0.02 \mathrm{~g}$, and permits the use of $0.10 \mathrm{~g}$ of high grade manganese ore, a decided advantage. As seen in series $\mathrm{A}$ and $\mathrm{B}$, the results with as much as $3 \mathrm{~g}$ iron present, are 
entirely satisfactory. The agreement of the sodium oxalate and manganese sulphate values will be discussed later.

(3) Acidity, Volume, Time of Standing, etc.-The results of several series of experiments to determine the effect of various conditions upon the bismuthate method are summarized in the following table:

TABLE IV

Effect of Conditions upon Bismuthate Standardization

( $\mathrm{KMnO}_{4}$ Solution $\mathrm{K}$ )

\begin{tabular}{|c|c|c|c|c|}
\hline Series & Mrethod & Mođification & $\begin{array}{l}\text { Determina- } \\
\text { tions }\end{array}$ & 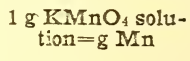 \\
\hline A 1 & $\mathrm{Na}_{2} \mathrm{C}_{2} \mathrm{O}_{4}$ & Standard, p. $726 \ldots$ & 6 & 0.001098 \\
\hline B 1 & $\mathrm{MnSO}_{4}$ & Standard, p. $732 \ldots \ldots \ldots \ldots \ldots$ & 9 & 1098 \\
\hline C 1 & $\mathrm{MnSO}_{4}$ & Initiai conc. $\mathrm{HNO}_{3}, 10$ per cent .......... & 3 & 1114 \\
\hline 2 & $\mathrm{MnSO}_{4}$ & Initial conc. $\mathrm{HNO}_{3}, 40$ per cent .......... & 3 & 1098 \\
\hline D 1 & $\mathrm{MnSO}_{4}$ & Initial volume, $150 \mathrm{cc} . . . . . . . .$. & 3 & 1098 \\
\hline $\mathrm{E} 1$ & $\mathrm{MnSO}_{4}$ & Shaken with bismuthate 15 sec.... & 3 & 1097 \\
\hline F 1 & $\mathrm{MnSO}_{4}$ & Stood before filtration $10 \mathrm{~min} . . .$. & 3 & 1097 \\
\hline 2 & $\mathrm{MnSO}_{4}$ & Stood before filtration $30 \mathrm{~min} . . . . . . . .$. & 1 & 1097 \\
\hline G 1 & $\mathrm{MnSO}_{4}$ & Stood after filtration $10 \mathrm{~min} . . . .$. . & 1 & 1097 \\
\hline 2 & $\mathrm{MnSO}_{4}$ & Stood after filtration $20 \mathrm{~min} . . . . . . . . . .$. & 1 & 1097 \\
\hline 3 & $\mathrm{MnSO}_{4}$ & Stood after filiration $30 \mathrm{~min} . . . . .$. & 1 & 1098 \\
\hline H 1 & $\mathrm{MnSO}_{4}$ & Stood after addition of $\mathrm{FeSO}_{4} 10 \mathrm{~min} . .$. & 1 & 1096 \\
\hline 2 & $\mathrm{MnSO}_{4}$ & Stood after addition of $\mathrm{FeSO}_{4} 30 \mathrm{~min} . . .$. & 1 & 1084 \\
\hline \multirow[t]{2}{*}{ I 1} & $\mathrm{NinSO}_{4}$ & Addition of $\mathrm{H}_{3} \mathrm{PO}_{4}-5 \mathrm{cc} \ldots \ldots \ldots \ldots \ldots$ & 3 & 1099 \\
\hline & & \multicolumn{2}{|c|}{ Mean of all $\mathrm{MnSO}_{4}$ values except $\mathrm{C}_{1}$ and $\mathrm{H}_{2} \ldots \ldots \ldots$. } & 1098 \\
\hline
\end{tabular}

Of the $\mathrm{MnSO}_{4}$ values given in Table IV, the individual determinations of all except those in $\mathrm{C}_{1}$ and $\mathrm{H}_{2}$ varied less than I part in 500 from the mean, showing that accurate results can be obtained over a very wide range of conditions. The only conditions found to produce appreciable errors were (a) deficiency of nitric acid and (b) allowing the solution to stand more than ro minutes after the addition of the ferrous sulphate, of which about Io cc excess was present. Since there is no occasion for either of these conditions to arise in good practice, the method may be considered accurate under all ordinary conditions of procedure, an important criterion for a standard method of analysis.

(4) Use of Phosphoric Acid.-The addition of this reagent as recommended by Dudley, was found convenient though not necessary, since with o.I $N$ solutions there was no difficulty in obtain- 
ing a sharp end point within $0.03 \mathrm{cc}$ of permanganate, without its use. If used, it should be added to the ferrous sulphate solution beforehand, rather than during the titration, since in the latter case a white precipitate, probably consisting of basic bismuth phosphate separates, rendering the end point slightly less distinct. With very large amounts of iron, e. g. 3-5 g, such as would have to be used if $\mathrm{Mn}$ in steel were determined with o. I $N$ permanganate, it was found that addition of phosphoric acid possesses no advantage, since it tends to produce a pink color, due probably to the formation of an acid ferric phosphate, ${ }^{40}$ which obscures the end point as much as does the ferric nitrate. The use of o.I $N$ solutions is therefore recommended only for manganese ores and similar high-grade products, in which the highest accuracy is desired.

(c) Probable Course of Reactions.-From Table IV, some light may be thrown upon the probable course of the reactions when manganese is oxidized by bismuthate. At least two reactions are probable (a) direct oxidation to $\mathrm{Mn}^{\mathrm{VII}}$ and (b) interaction of unoxidized $\mathrm{Mn}^{\mathrm{II}}$ with the $\mathrm{Mnvu}^{\mathrm{vu}}$, precipitating $\mathrm{Mn}^{\mathrm{rv}}$, which is then removed from the oxidizing influence of the bismuthate. If these two reactions may take place, the problem resolves itself into a determination of the conditions under which reaction (a) will be accelerated and (b) will be retarded, so that (a) goes practically to completion before (b) can take place to an appreciable extent. The favorable conditions for (b) as conducted in the Volhard method, for example, are slight acidity and high temperature; which should therefore be avoided in the bismuthate oxidation.' That this explanation is plausible is shown by a comparison of $\mathrm{C}_{1}$ and $\mathrm{C}_{2}$. That complete oxidation may be effected in a short time is indicated in $\mathrm{E}_{1}$; in which connection the necessity for thorough agitation must be emphasized. Other experiments, not recorded here, showed that with $0.05 \mathrm{~g}$ or more of $\mathrm{Mn}$, complete oxidation could not be effected if the solution was not thoroughly, agitated. In the earlier experiments in this investigation, the solutions were artificially cooled to about $5^{\circ}$; but after it was found that results at room temperature, $20^{\circ}$ to $25^{\circ}$, were entirely satisfactory, artificial cooling was dispensed with.

40 Errlenmeyer and Heinrich: Ann. Chem., 190, p. I9r: 1877.

$73764^{\circ}-\mathrm{r} 3-9$ 
(d) Conditions Recommended.-Correct results can be obtained under the following conditions: To the manganese solution containing 20 to 40 per cent nitric acid (free from nitrous acid) in a volume of 50 to I $50 \mathrm{cc}$, add a slight excess of bismuthate (usually 0.5 to $\mathrm{I} .0 \mathrm{~g}$ ), agitate thoroughly for about one-half minute, wash down the sides of the flask with 3 per cent nitric acid, filter through asbestus, wash with roo cc of 3 per cent nitric acid, add a slight. excess of ferrous sulphate, and titrate at once with permanganate. For iron and steel, $0.03 N$ solutions as described by Blair are satisfactory.

For ores and ferromanganese o. $N$ permanganate solution may be employed, and an amount of material containing about $0.05 \mathrm{~g}$ manganese. For the rapid solution of ores, a method recommended by Blair ${ }^{41}$ has been found convenient. One $g$ of the ore is fused in a large platinum crucible with o $\mathrm{g}$ potassium bisulphate, $\mathrm{I} \mathrm{g}$ of sodium sulphite and $0.5 \mathrm{~g}$ sodium fluoride. The heating should be very slow till effervescence ceases. After complete fusion the product is cooled, then heated carefully with io cc concentrated sulphuric acid, cooled, dissolved in water, and made up to a definite volume. The slight precipitate of barium sulphate usually present will not influence the manganese determination.

\section{AGREEMENT OF VALUES DERIVED FROM SODIUM OXALATE AND MANGANOUS SULPHATE}

TABLE $\mathrm{V}$

Comparison of $\mathrm{Na}_{2} \mathrm{C}_{2} \mathrm{O}_{4}$ and $\mathrm{MnSO}_{4}$ values

\begin{tabular}{|c|c|c|c|c|}
\hline \multirow{3}{*}{$\begin{array}{l}\text { Permanganate } \\
\text { solution }\end{array}$} & \multicolumn{4}{|c|}{ Manganese values derived from- } \\
\hline & \multicolumn{2}{|c|}{ Sodium oxalate } & \multicolumn{2}{|c|}{ Manganese sulphate } \\
\hline & Determinations & $1 \mathrm{~g} \mathrm{KMnO}_{1}=\mathrm{g} \mathrm{Mn}$ & Determinations & $1 \mathrm{~g} \mathrm{KMnO}_{4}=\mathrm{g} \mathrm{Mn}$ \\
\hline $\mathbf{A}_{1}$ & 3 & 0.0003465 & 3 & 0.0003469 \\
\hline $\mathbf{A}_{2}$ & 4 & 0.0003462 & 3 & 0.0003462 \\
\hline $\mathbf{B}$ & 6 & 0.0003454 & 5 & 0.0003458 \\
\hline$E$ & 9 & 0.001096 & 4 & 0.001094 \\
\hline G & 7 & 0.001091 & 5 & 0.001090 \\
\hline I & 18 & 0.001091 & 28 & 0.001089 \\
\hline $\mathrm{K}$ & 6 & 0.001098 & 29 & 0.001098 \\
\hline
\end{tabular}


Consideration of the values in Table $\mathrm{V}$ shows plainly that no greater difference than I part in 500 exists between the results derived from the sodium oxalate and manganese sulphate, respectively, instead of the former values being I per cent lower, as claimed by Brinton and others. In fact in the case of the o.I $N$ solutions, the only ones in which an accuracy of more than I part in 500 is realizable, the manganous sulphate values show a tendency to be from one to two parts per thousand lower than the sodium oxalate results. It is at least interesting though perhaps not significant, that if the value 55.00 instead of 54.93 be used for the atomic weight of manganese, the results with the o. I $N$ solutions agree in every case to within I part in 1000.

\section{ANALYSIS OF PURE PERMANGANATE CRYSTALS}

Additional evidence of the correctness of the above values was found in the analysis of the pure permanganate prepared as described on page 721 , which contained 0.38 per cent water. The salt should therefore contain 34.63 per cent manganese, instead of 34.76 per cent, the theoretical content for pure anhydrous $\mathrm{KMnO}_{4}$. This difference with specially purified permanganate indicates clearly the probable presence of water as well as manganese peroxide in C. P. permanganate, rendering it unsuitable as a primary standard. Manganese was determined gravimetrically by precipitation with ammonium sulphide; the manganese sulphide being washed with dilute ammonium sulphide, ignited in a weighed crucible, treated with sulphrous and sulphuric acids, evaporated, heated to $450^{\circ}$ to constant weight, and weighed as $\mathrm{MnSO}_{4}$. The manganese in the filtrates was determined colorimetrically. Results of duplicate analyses were 34.70 per cent and 34.66 per cent, the mean 34.68 per cent agreeing closely with the theoretical value 34.63 per cent. The oxidizing value of this permanganate was determined by means of solutions $A_{1}, A_{2}$, and $\mathrm{E}$ (Table $\mathrm{V}$ ) which were prepared by the solution of an exact weight of the salt in a definite weight of solution. In $A_{1}$ and $A_{2}$, exactly I $\mathrm{g} \mathrm{KMnO}_{4}$ was dissolved and diluted to I $\mathrm{kg}$; yielding solutions having an oxidizing value equivalent to 34.65 per cent $\mathrm{Mn}$ (average of all sodium oxalate and manganous sulphate values for $A_{1}$ and 
$A_{2}$ ). Solution $E$ contained 3.I $606 \mathrm{~g}$ of the salt per kilogram, and possessed an oxidizing power equivalent to 34.65 per cent $\mathrm{Mn}$, (derived from the average of all sodium oxalate and manganous sulphate values for solution $\mathrm{E}$ ). Solutions $\mathrm{B}, \mathrm{G}, \mathrm{I}$, and $\mathrm{K}$ were prepared of only approximately the desired strength, and the results have no relation to the composition of the solid permanganate employed.

\section{ANALYSIS OF MANGANESE ORES}

Analyses of the Bureau of Standards Manganese Ore (Standard Sample No. 25) by means of permanganate I, gave as the average of nine determinations, 56.30 per cent $\mathrm{Mn}$ upon the basis of the sodium oxalate standardization, and 56.20 per cent if calculated from the manganous sulphate. These results are in good agreement with the mean value 56.36 per cent derived from all determinations upon the certificate, and with the value 56.33 formerly found by the author with the bismuthate method, using sodium oxalate as the standard. Unfortunately comparisons based upon this sample are not necessarily conclusive, since the mean value 56.36 per cent is derived from results ranging from 56.15 to 56.63 , obtained by eight chemists using a variety of methods, the lack of agreement of which is illustrated. If the bismuthate results by the author are correct, a conclusion made highly probable by the work here described, the value of the ore lies between 56.20 and 56.30 per cent manganese; and many of the values found by other methods, by the author and others, are too high. That the tendency of many commercial methods is to yield results higher than those by the method here recommended, is shown in the results of analyses of three manganese ores by the author and two well known commercial chemists.

TABLE VI

Analyses of Manganese Ores

\begin{tabular}{|c|c|c|c|c|}
\hline Analyst & Method & Ore I & Ore II & Ore III \\
\hline $\mathbf{A}$ & Bismuthate. & 52.47 & 52.53 & 50.50 \\
\hline B & Modified acetate. & 52.40 & 52.29 & 50.52 \\
\hline Author & Bismuthate.. & 51.93 & 52.03 & 50.12 \\
\hline
\end{tabular}


The differences here shown, amounting to 0.8 to I.o per cent of the manganese present, are by no means insignificant. The discrepancy between the results by $\mathrm{A}$ and the author, both using the bismuthate method, was found to be due mainly to differences in the method of standardizing the manganous sulphate solution. (See p. 730.) These results show clearly the necessity for a thorough investigation of other methods for determining manganese, in order that accurate results may be uniformly obtained.

\section{SUMMARY}

I. To obtain normal anhydrous manganous sulphate, the salt may and must be heated for a considerable time at $450^{\circ}$ to $500^{\circ}$, i. e., just below red heat.

2. Standardizations of permanganate solutions (both $0.03 \mathrm{~N}$ and o.I $N$ ) by means of sodium oxalate, manganous sulphate, and solid permanganate agree within the experimental error, which in the bismuthate method could not be reduced much below I part in 500. Taken together with the agreement of sodium oxalate and iron values, and the experiments upon the reduction and reoxidation of permanganate, the absolute accuracy of the above results, within the experimental limits, is rendered almost certain.

3. In view of the difficulties attending the use of manganous sulphate, standardization by means of sodium oxalate, under definite, but easily realizable conditions, is recommended.

4. Results by the bismuthate method are accurate over a very wide range of conditions, for amounts of manganese up to $0.05 \mathrm{~g}$.

5. For accurate determinations on rich ores, etc., the use of o. I $N$ permanganate is recommended, while for iron and steel the method described by Blair is entirely satisfactory.

6. The statement of Blair that "this method for materials containing small amounts of manganese, say up to 2 per cent, is more accurate than any other method, volumetric or gravimetric," may be extended to include materials containing large amounts of manganese.

7. Filtered permanganate solutions preserve their strength when exposed to diffused light, if protected from dust and reducing substances. In the presence of the latter, alkaline permanganate solutions decompose less rapidly than do neutral solutions. 
The author desires to express his thanks to Dr. W. F. Hillebrand for valuable suggestions and advice during the course of this investigation.

WASHINGTON, June 2I, I9I 2. 